\title{
Transdermal hormone replacement therapy with nanostructured medicines
}

\author{
Fatemeh Abdi ${ }^{1}$, Tayebeh Darooneh ${ }^{2}$, Maryam Ghorbani ${ }^{3}$, \\ Farzaneh Banihashemi ${ }^{4}$, Nasibeh Roozbeh ${ }^{4}$
}

\begin{abstract}
'Student Research Committee, Nursing and Midwifery Faculty, Shahid Beheshti University of Medical Sciences, Tehran, Iran ${ }^{2}$ Department of Reproductive Health, Nursing and Midwifery Faculty, Shahid Beheshti University of Medical Sciences, Tehran, Iran ${ }^{3}$ Department of Reproductive Health, Nursing and Midwifery Faculty, Shahroud University of Medical Sciences, Shahroud, Iran

${ }^{4}$ Mother and Child Welfare Research Center, Hormozgan Universiy of Medical Sciences, Bandar Abbas, Iran
\end{abstract}

\begin{abstract}
Objectives: Due to hormonal changes during the menopause, women experience a variety of perimenopause and postmenopause symptoms. This review examines the various aspects of nanostructured hormone therapy and its application in the treatments of menopausal symptoms.

Material and methods: Excerpta Medica DataBase, Medical Literature Analysis and Retrieval System Online, Web of Science and Google Scholar were searched basing on the Preferred Reporting Items for Systematic Reviews and Meta-Analyses guidelines. Seven eligible studies out of 51 related papers, which satisfied the initial search criteria, were extracted and carefully reviewed to clarify the role of nanomedicine in maintaining postmenopausal women's health.

Results: Review of the seven eligible studies confirmed nanostructured hormone therapy as a safe and effective method for the alleviation of menopausal symptoms. According to the existing studies, nanostructured hormone therapy decreased the mean daily frequency and severity of menopausal symptoms.

Conclusion: The use of transdermal nanoformulations in hormone therapy can relieve climacteric symptoms and prevent other postmenopausal symptoms.
\end{abstract}

Key words: menopause, hormone therapy, nanostructured medicine

Ginekologia Polska 2017; 88, 2: 103-108

\section{INTRODUCTION}

Menopause is an evolutionary process and a significant stage in any woman's life [1, 2]. Changes during this stage increase the risk of diseases in women and make menopause the second cause of disability-adjusted life years (after cardiovascular diseases) in 45-60 year old women [1, 3]. Although recent medical advances and the consequent rise in life expectancy (from 40 to 84 years) have increased the number of postmenopausal women throughout the world [4], the age of menopause has remained almost constant, i.e. postmenopausal years still constitute about one-third of women's lives [5]. Therefore, menopause is a major health issue which management will improve women's quality of life and health status [6].

Hormones play a key role in human health and regulation of vital processes. Due to hormonal changes during the menopause, women experience a variety of menopausal symptoms [1] including hot flushes, night sweats, sleep disorders, anxiety, irritability, and mood swings [7]. The management of such vasomotor symptoms, affecting the quality of life in $60-80 \%$ of postmenopausal women, requires hormone replacement therapy (HRT) [5]. However, a small proportion of women who experience these symptoms tend to seek medical treatment [8]. While the application of estrogen alone or in combination with progesterone (combined HRT) has long been considered as the treatment of choice for menopausal symptoms [9], the results of Women's Health Initiative (WHI) highlighted the health risks associated with HRT and indicated the need for alternative therapies [10]. Despite the widespread use of HRT in the alleviation of menopause symptoms, limited knowledge is 
available about the efficacy of transdermal HRT (THRT) as an alternative to HRT in women who, for any reason, cannot use other routes of drug administration [11].

Nanomedicine, i.e. the application of nanoscience in various healthcare fields including the prevention, diagnosis, and treatment of diseases, has attracted increasing attention in today's world [12]. Nanoparticles are between 1 and 200 nanometers in size and have either chemical or biological origin [13]. In nanomedicine research, specific nanoparticles are designed for drug delivery. These carriers improve the biodistribution of drugs by delivering active molecules to target tissues while protecting adjacent healthy tissues [14]. Controlled release, targeted delivery, increased drug solubility and absorption, fewer side effects, lower frequency of drug administration and the consequent reduction in drug toxicity, and longer duration of drug action are among the numerous advantages of nanomedicines. Nanotechnology has in fact opened up new horizons in effective drug targeting through drug carrier systems [15].

Dermal delivery is one of the most important drug delivery routes in novel pharmaceutics. In transdermal drug delivery, the drug moves along different layers of the skin and creates the desired response by entering the systemic circulation [16]. Nanocarriers can either remain unchanged after penetration into the skin or break down and release the active components into various layers of the skin [17]. Transdermal drug delivery has several benefits: it maintains constant plasma levels of the drug for longer periods of time (compared to oral administration), eliminates first-pass metabolism and drug destruction by digestive agents, and increases patient compliance [18].

The development of nanotechnology can potentially facilitate health promotion among older adults [19]. As a result of increasing attention to nanotechnology in dealing with health challenges faced by the older population [20], great advances have been made in the design of nanoformulation for various conditions including breast cancer, hearing loss, and cardiovascular and central nervous system diseases [19]. New evidence has also suggested the unique properties of nanostructured HRT in the management of climacterium symptoms [21]. However, since the exact benefits of such protocols are still under debate, the present study reviewed different aspects of nanostructured HRT and its applications in alleviating menopausal symptoms.

\section{MATERIAL AND METHODS}

Literature search strategy

The guidelines of Preferred Reporting Items for Systematic Reviews and Meta-Analyses (PRISMA) and Cochrane Handbook for Systematic Reviews of Interventions were adopted to search Medical Literature Analysis and Retrieval System Online (MEDLINE), Cochrane, Excerpta Medica DataBase
(EMBASE), Web of Science, and Google Scholar databases for papers published until February, 2016. A number of key terms including menopausal symptoms, perimenopause, postmenopause, climacteric, hormone therapy nanostructured medicine were used in all searchers. The keywords in each group were combined using the Boolean operator "OR". All searches contained at least one keyword from each group combined using the Boolean operator "AND". Papers in all languages would be surveyed if they reported placebo-controlled clinical trials on the use of nanostructured transdermal HRT to relieve menopausal symptoms in perimenopausal or postmenopausal women. Studies with only one active control group and without quantitative outcome data were excluded.

\section{Study selection and data extraction}

Two independent reviewers (F.A. and T.D.) used the above-mentioned set of inclusion and exclusion criteria for the preliminary extraction of the studies. Cases of disagreement about the eligibility of studies were resolved by consulting a third reviewer. The first author's name, year of publication, study type and design, number of participants, and evaluated outcomes were extracted from all eligible papers.

\section{Quality Appraisal}

The systematic review was reported following the PRISMA checklist. Methodological elements including data collection, accurate description of sampling, study setting, characteristics of participants and inclusion and exclusion criteria were evaluated to ensure the quality of the selected papers. All eligible studies were carefully reviewed. The quality of trials was assessed using the Cochrane Collaboration's tool for assessing the risk of bias in randomized trials.

\section{RESULTS}

A total of 119 related papers were identified, 51 of which, satisfied the search criteria, but only 15 papers containing the application of nanotechnology in the management of menopausal symptoms were potentially retrievable. Ultimately, seven eligible studies were included and thoroughly reviewed. Figure 1 presents a flow diagram of the study selection procedure.

Most studies confirmed nanostructured HRT as a safe and effective method of restoring normal estradiol serum levels and alleviating menopausal symptoms. The application of transdermal nanoformulations for HRT was also found to relieve the climacteric syndrome and prevent several menopausal symptoms. A main variable measured by the majority of researchers was the mean daily reduction in the frequency of menopausal symptoms during the course of the treatment. Although limited knowledge about the efficacy of nanomedicines in decreasing menopausal symptoms is available, the reviewed studies suggested the positive effects of 
nanostructured HRT on menopausal symptoms and clinical parameters. Another advantage of such nanomedicines was their fewer side effects compared to conventional medicines used in HRT. Table 1 summarizes the reviewed papers.

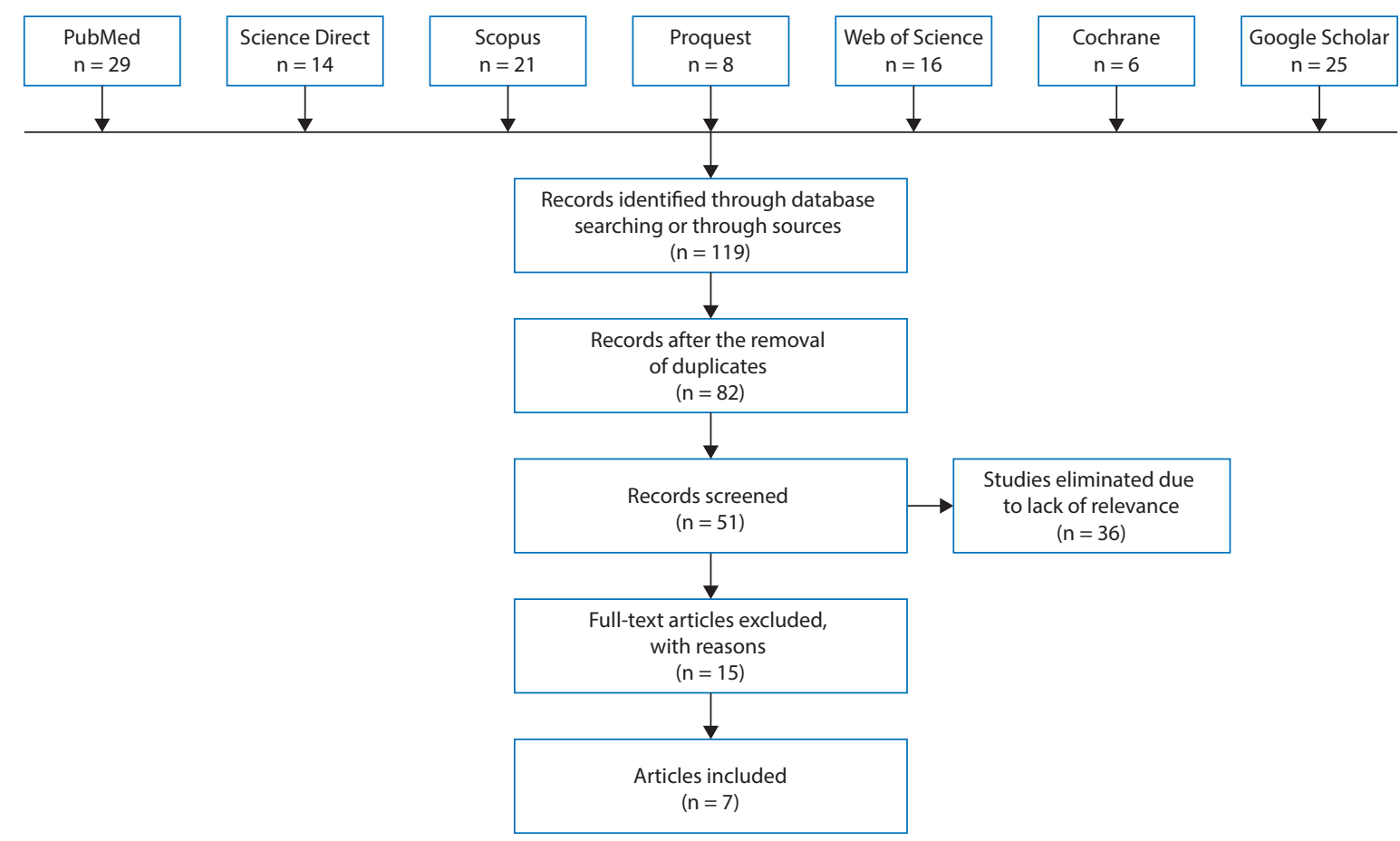

Figure 1. The algorithm of study selection for the systematic review

Table 1. Reviewed papers about the application of nanostructured HRT in the treatment of menopausal symptoms

\begin{tabular}{|c|c|}
\hline $\begin{array}{l}1^{\text {st }} \text { author, } \\
\text { year of publication }\end{array}$ & Research information \\
\hline $\begin{array}{l}\text { Simon, } 2006 \\
{[22]}\end{array}$ & $\begin{array}{l}\text { Title: Estradiol in micellar nanoparticles: the efficacy and safety of a novel transdermal drug-delivery technology in the } \\
\text { management of moderate to severe vasomotor symptoms } \\
\text { Type of study: Double-blind randomized placebo-controlled clinical trial } \\
\text { Participants: } 200 \text { postmenopausal women } \\
\text { Study design: A multi-center double-blind randomized placebo-controlled clinical trial with a three-week screening period } \\
\text { followed by one week of treatment with a placebo emulsion and then } 12 \text { weeks of treatment with either placebo or a micellar } \\
\text { nanoparticle estradiol emulsion (MNPEE). Women were randomly allocated to placebo and MNPEE groups (at a } 1: 1 \text { ratio) } \\
\text { The MNPEE group received } 3.45 \mathrm{~g} / \text { day of an estradiol emulsion, i.e. } 8.6 \mathrm{mg} / \text { day estradiol. The placebo group received similar } \\
\text { amounts of a placebo emulsion. The primary efficacy variable was the reduction in the number of moderate-severe hot flushes } \\
\text { per day at the fourth and } 12^{\text {th }} \text { weeks. The adverse effects of treatments were also evaluated throughout the study } \\
\text { Outcomes: The treatment could effectively reduce the frequency of moderate-severe hot flushes per day from baseline to } \\
\text { the } 12^{\text {th }} \text { week ( }-11.1 \pm 6.8 \text { times per day after estradiol use and }-7.2 \pm 5.4 \text { times per day after placebo use; }<<0.001 \text { ). The } \\
\text { efficacy of MNPEE in reducing the frequency of hot flushes was significantly higher than that of placebo at from weeks three } \\
\text { to } 12 \text {. At the } 12^{\text {th }} \text { week, MNPEE could decrease the daily frequency of hot flushes by } 11.1 \text { times }\end{array}$ \\
\hline $\begin{array}{l}\text { Botelho, } 2014 \\
\text { [21] }\end{array}$ & $\begin{array}{l}\text { Title: Nanostructured transdermal hormone replacement therapy for relieving menopausal symptoms: a confocal } \\
\text { Raman spectroscopy study } \\
\text { Type of study: Long-term clinical trial } \\
\text { Participants: } 66 \text { postmenopausal women with climacteric syndrome } \\
\text { Study design: In order to provide a hormone secretion pattern similar to that of normal ovaries, the participants were } \\
\text { asked to apply transdermal nanostructured progesterone and estrogen formulations on their forearms every day for } \\
60 \text { months. The assessment of hormones in different skin layers was conducted using confocal Raman spectroscopy. The } \\
\text { participants' blood pressure, serum levels of estradiol and follicle-stimulating hormone (FSH), clinical parameters, bilateral } \\
\text { mammographic findings, and severity of symptoms were evaluated during the } 60 \text {-month period of the study } \\
\text { Outcomes: After } 60 \text { months of treatment, } 92.5 \% \text { of the participants reported reductions in the severity of climacteric } \\
\text { symptoms. Significant changes in serum levels of estradiol and FSH were observed after treatment. Serum FSH levels } \\
\text { decreased from } 82.04 \pm 4.9 \mathrm{IU} / \mathrm{mL} \text { at baseline to } 57.12 \pm 4.1 \mathrm{IU} / \mathrm{mL} \text { after } 60 \text { months. The results of bilateral mammography } \\
\text { were normal in all women. No particular adverse health events were detected during the treatment course }\end{array}$ \\
\hline
\end{tabular}




\begin{tabular}{|c|c|}
\hline $\begin{array}{l}1^{\text {st }} \text { author, } \\
\text { year of publication }\end{array}$ & Research information \\
\hline $\begin{array}{l}\text { Boxenbaum, } 2002 \\
\text { [23] }\end{array}$ & $\begin{array}{l}\text { Title: Pharmacokinetics of Estrasorb, a topical lotion for treatment of postmenopausal vasomotor symptoms } \\
\text { Type of study: Phase I clinical trial } \\
\text { Participants: Eight postmenopausal women } \\
\text { Study design: The first phase of the study was conducted on a group of postmenopausal women and pharmacokinetics of } \\
\text { a micellar nanoparticle estradiol emulsion (MNPEE) containing } 7.5 \mathrm{mg} \text { estradiol was evaluated once daily } \\
\text { Outcomes: The daily frequency of moderate-severe hot flushes was reduced following the treatment. Since the final half- } \\
\text { life of estradiol was about } 2.4 \text { days (with a cumulative index of four), MNPEE had a stable drug release. The daily systemic } \\
\text { dose of estradiol delivered was estimated at } 0.05 \mathrm{mg}\end{array}$ \\
\hline $\begin{array}{l}\text { Gonzaga, } 2012 \\
\text { [11] }\end{array}$ & $\begin{array}{l}\text { Title: Nanotechnology in hormone replacement therapy: Safety and efficacy of transdermal estriol and estradiol } \\
\text { nanoparticles after } 5 \text { years of follow-up } \\
\text { Type of study: Clinical trial } \\
\text { Participants: } 122 \text { postmenopausal women with natural menopause } \\
\text { Study design: The participants received a transdermal formulation of estriol }(0.1 \%)+\text { estradiol }(0.25 \%) \text { on their right } \\
\text { forearm for five years. The aim was to restore serum levels of hormones and to alleviate menopausal symptoms. The } \\
\text { reduction in symptoms (based on self-report), serum estradiol levels, weight, blood pressure, and bilateral mammography } \\
\text { findings were measured at baseline and after } 60 \text { months of treatment } \\
\text { Outcomes: The transdermal estradiol nanoformulation enhanced the measured clinical parameters. Patients' satisfaction } \\
\text { was calculated as } 92 \% \text {. While serum estradiol levels changed significantly after treatment, no significant differences in } \\
\text { weight and systolic and diastolic blood pressure were observed during the course of the study }\end{array}$ \\
\hline $\begin{array}{l}\text { Simon, } 2007 \\
\text { [24] }\end{array}$ & $\begin{array}{l}\text { Title: Estradiol topical emulsion (ETE) for the treatment of moderate-to-severe vasomotor symptoms associated with } \\
\text { menopause } \\
\text { Type of study: Phase Il placebo-controlled clinical trial } \\
\text { Participants: } 125 \text { postmenopausal women with moderate to severe hot flushes } \\
\text { Study design: The efficacy and safety of three doses of ETE }(1.15,2.30 \text {, or } 3.45 \mathrm{~g} \text { of emulsion containing } 2.5 \mathrm{mg} / \mathrm{g} \text { estradiol) } \\
\text { was evaluated in } 125 \text { postmenopausal women. The treatment course lasted for } 28 \text { days. The frequency and severity of hot } \\
\text { flushes were measured during a one-week treatment with placebo and the } 28 \text {-day treatment with ETE } \\
\text { Outcomes: After } 4 \text { weeks of treatment with the confirmed dosage of ETE, } 45 \% \text { of women reported complete relief of } \\
\text { moderate to severe hot flushes. This rate was } 9 \% \text { in the placebo group. Maximum reduction in hot flushes occurred after } \\
12 \text { weeks of receiving ETE }(-11.1 \pm 6.8 \text { hot flushes per day in the ETE group vs. }-7.2 \pm 5.4 \text { hot flushes per day in the placebo } \\
\text { group; } p<0.001)\end{array}$ \\
\hline $\begin{array}{l}\text { Taylor, } 2008 \\
\text { [25] }\end{array}$ & $\begin{array}{l}\text { Title: Absorption, bioavailability, and partner transfer of estradiol from a topical emulsion } \\
\text { Type of study: Open-label, non-randomized clinical trial } \\
\text { Participants: } 14 \text { postmenopausal women and their male partners } \\
\text { Study design: Women were asked to apply } 1.74 \mathrm{~g} / \text { day of a topical estradiol emulsion (containing } 2.5 \mathrm{mg} / \mathrm{g} \text { estradiol) to } \\
\text { each leg on two consecutive days. In order to expose their partners, women were also asked to maintain close skin-to-skin } \\
\text { contact with their male partners two and eight hours after the application of the emulsion } \\
\text { Outcomes: Serum levels of estradiol, estrone, and estrone sulfate were evaluated in both female and male subjects. The } \\
\text { mean estradiol levels in women were } 2.9 \pm 1.5,15.3 \pm 14.8 \text {, and } 27.6 \pm 22.7 \mathrm{pg} / \mathrm{mL} \text { at baseline, the first day of treatment, and } \\
\text { the second day, respectively. Their geometric mean fold ratio for the area under the serum level-time curve from } 0-24 \text { hours } \\
\text { was } 1.25 \text {. Close skin-to-skin contact with women at application sites transferred estradiol to their male partners. While } \\
\text { estradiol levels in men significantly increased after exposure, all levels remained in the normal range }\end{array}$ \\
\hline $\begin{array}{l}\text { Botelho, } 2015 \\
\text { [26] }\end{array}$ & $\begin{array}{l}\text { Title: Effects of a transdermal testosterone metered-dose nanoemulsion in peri- and postmenopausal women: a novel } \\
\text { protocol for treating low libido } \\
\text { Type of study: Clinical trial } \\
\text { Participants: } 24 \text { women (mean age: } 51.7 \text { years) with decreased libido } \\
\text { Study design: Women were asked to apply a novel transdermal formulation containing } 500 \mu \mathrm{g} / \text { day testosterone on } \\
\text { their right arm. The treatment continued for } 12 \text { weeks. Breast examination and blood tests were performed four weeks } \\
\text { before treatment. A questionnaire was administered to assess women's complaints about decreased libido before and } \\
\text { after treatment. Clinical and laboratory parameters including decreased libido, serum testosterone, insulin, and C-reactive } \\
\text { protein levels, weight, blood pressure, body mass index (BMI), and waist circumference were measured } \\
\text { Outcomes: The mean serum testosterone levels significantly increased after } 12 \text { weeks of treatments. No adverse } \\
\text { androgenic effects or significant changes in the participants' weight were observed during the course of treatment. } \\
\text { However, the clinical parameters significantly improved after treatment. While only } 38 \% \text { of the participants were satisfied } \\
\text { with their sexual function before treatment, this rate increased to } 82 \% \text { after treatment }\end{array}$ \\
\hline
\end{tabular}

\section{DISCUSSION}

The findings of the present review highlighted the potential benefits of nanostructured medicines in alleviating peri- and postmenopause symptoms. Although the existing epidemiological data suggest the efficacy of nanomedicines in the management of menopausal symptoms in women of many nations, further research is warranted to confirm such effects. 
Nanotechnology is a novel field of science. Nanostructured medicines have shown unique and remarkable properties such as skin absorption. Controlled release of drugs is another fascinating property of nanomedicines which may play a major role in public health and promotion in the future [11]. A variety of techniques, including the use of nanomedicines, have been applied in transdermal drug delivery to increase the penetration of therapeutic molecules into the skin [17]. Due to their high loading capacity, long release time, and high transdermal penetration caused by their mechanical flexion (which enables them to reach even lymph nodes), nanoparticles based on polymers and polysaccharides, as well as nanostructured lipid carriers (NLCs) and solid lipid nanoparticles (SLNs), have received increasing attention during the recent years [27]. Nanomedicines are drug carriers specifically designed to deliver active molecules to the target tissues while protecting healthy tissues. Such a process is believed to enhance the biodistribution of drugs [14]. Accurate drug targeting will minimize not only the required dose for effective treatment, but also the possible drug side effects [28]. De Vargas et al. designed a procedure to develop topical hydrogels containing genistein-loaded nanoemulsions. The result was monodisperse nanoemulsions (in the $250 \mathrm{~nm}$ range) with low viscosity and negative zeta potential. The application of these nanoemulsions caused a slow flow of genistein into the skin. Therefore, the researchers recommended hydrogels containing loaded nanoemulsions as effective formulations for transdermal delivery of isoflavones [29].

According to the current review, researchers around the world are interested in the use of nanotechnology for the management of menopausal symptoms. Botelho et al. reported the use of nanoparticles in transdermal HRT as a safe and efficient controlled drug release system to alleviate menopausal symptoms [21]. In another study, Botelho et al. evaluated the efficacy of a novel transdermal delivery system using a nanostructured formulation containing testosterone and progesterone. They found the treatment to improved satisfaction with sexual performance from $38 \%$ to $82 \%$ and concluded that increasing testosterone levels could effectively resolve climacteric symptoms in postmenopausal women with decreased libido [26]. Gonzaga et al. examined the safety and efficacy of a new protocol for the application of transdermal estriol and estradiol nanoparticles in HRT.Their findings indicted the efficacy of the developed transdermal drug delivery system. The treatment improved clinical parameters but had no significant effects on women's weight or blood pressure. The rate of satisfaction with treatment was $92 \%$ [11]. Taylor et al. found that close skin-to-skin contact with postmenopausal women who applied a topical estradiol emulsion resulted in the transfer of estradiol from women to their partners. Although this exposure significantly increased estradiol levels in men, the levels of this hormone remained in the normal range [25]. Estrasorb ${ }^{\circledR}$ is an estradiol topical emulsion which uses micellar nanoparticles for drug delivery. When applied on the skin, micellar nanoparticles accumulate on the outer layer of the skin and the estradiol emulsion gradually penetrates into the skin and reaches blood circulation. Estrasorb ${ }^{\circledR}$ contains $2.5 \mathrm{mg} / \mathrm{g}$ estradiol hemihydrate and its pharmacokinetic profile suggests minimal changes in serum levels of estradiol [30]. Transdermal hormone delivery systems (THDSs) consist of a backing layer and an adjoining adhesive polymer matrix. In order for a THDS to be effective, the matrix should contain a minimal amount of the hormone which delivery is improved by one or more skin permeation-enhancing agents. With a THDS, effective daily doses of progesterone and estrogen can be delivered through a small area of the skin [31].

In a multicenter trial, Simon suggested micellar nanoparticle estradiol emulsion (MNPEE) as an effective, safe, and well-tolerated technology for reducing the frequency and severity of moderate to severe vasomotor symptoms [22]. Drug carriers enhance the physicochemical properties of drugs, facilitate the penetration of drug molecules into the skin, and improve skin permeation by skin hydration and interaction with skin lipids [32]. Case-control studies have shown a lower risk of venous thromboembolism (VTE) with transdermal estrogen therapy than with the oral administration of estrogen [33]. This finding was confirmed by a cohort study in which transdermal estrogens and the risk of VTE recurrence were not correlated [34]. A case-control study compared the risk of stroke following transdermal and oral HRT and concluded that transdermal HRT did not increase the risk of stroke [35].

In their attempts to provide insight into the application and effects of nanomedicine on common age-related health issues, recent studies have described the fundamental concepts and clinical applications of this modern science in promoting elderly health. Apparently, the development of nanotechnology can potentially lead to genomic and proteomic discoveries which improve elderly health [19].

\section{CONCLUSIONS}

In conclusion, nanostructured medicines can play a role in a cure of menopausal symptoms by ensuring that a sufficient amount of the drug enters the body. Nevertheless, the amount of drug loading along with control of drug release and drug penetration into blood circulation are still major challenges in the application of transdermal drug delivery to manage premenopause and postmenopause symptoms. Further studies are hence required to clarify the efficacy of nanoparticles in alleviating menopausal symptoms. We hope that this paper has illuminated the remarkable and extensive implications of nanotechnology in enhancing the life expectancy, health, and independence of older adults. 


\section{Strengths and limitations of this study}

- This review examines the various aspects of nanostructured hormone therapy and its application in the treatments of climacterium symptoms.

- Systematic reviews will provide the highest level of evidence for informed decisions. To the best of our knowledge, no systematic review has been conducted on this topic.

- Two independent authors will screen and extract the records.

- One limitation of this study is the lack of studies in nanotechnology approaches in the management of peri- and postmenopausal symptoms.

\section{ACKNOWLEDGMENT}

We are grateful for the helpful comments of anonymous referees.

\section{Conflict of interest}

None declared.

\section{REFERENCES}

1. Abdi F, Mobedi H, Mosaffa N, et al. Hormone Therapy for Relieving Postmenopausal Vasomotor Symptoms: A Systematic Review. Arch Iran Med. 2016; 19(2): 141-146, doi: 0161902/AIM.0013, indexed in Pubmed: 26838086.

2. Abdi F, Kazemi F, Ramezani Tehrani F, et al. Protocol for systematic review and meta-analysis: hop (Humulus lupulus L.) for menopausal vasomotor symptoms. BMJ Open. 2016; 6(4): e010734, doi: 10.1136/bmjopen-2015-010734, indexed in Pubmed: 27105715.

3. Heydari L, Sohrabi Z, Sayehmiri F, et al. Effect of Herbaceous Medicines effective in hot flashes of Menopause women: a systematic Review and Meta-Analysis in Iran. The Iranian Journal of Obstetrics, Gynecology And Infertility. 2014; 17: 16-25.

4. Yazdkhasti M, Simbar M, Abdi F. Empowerment and coping strategies in menopause women: a review. Iran Red Crescent Med J. 2015; 17(3): e18944, doi: 10.5812/ircmj.18944, indexed in Pubmed: 26019897.

5. Al-Safi ZA, Santoro N. Menopausal hormone therapy and menopausal symptoms. Fertil Steril. 2014; 101(4): 905-915, doi: 10.1016/j.fertnstert.2014.02.032, indexed in Pubmed: 24613533.

6. Rotem M, Kushnir T, Levine R, et al. A psycho-educational program for improving women's attitudes and coping with menopause symptoms. J Obstet Gynecol Neonatal Nurs. 2005; 34(2): 233-240, doi: 10.1177/0884217504274417, indexed in Pubmed: 15781600.

7. Crowe B. The Effects of Yoga Participation on Symptoms Associated with Menopause: A Mixed Methods Study. ; 2013.

8. National Collaborating Centre for Ws, Children's H. National Institute for Health and Care Excellence: Clinical Guidelines. Menopause: Full Guideline. London: National Institute for Health and Care Excellence (UK) Copyright. Success Strategies From Women in STEM. 2015, doi: 10.1016/b978-0-12-397181-4.00015-3.

9. Reid R, Blake J, Abramson B, [et al]. Menopause and osteoporosis update 2009. J Obstet Gynaecol Can. 2009;31(1 Suppl 1):S27-30.

10. Cedars MI. Introduction: menopausal hormone therapy: where are we today? Fertil Steril. 2014; 101(4): 885-886, doi: 10.1016/j.fertnstert.2014.02.026, indexed in Pubmed: 24613540.

11. Gonzaga LW, Botelho MA, QueirozDB, [et al].Nanotechnology in hormone replacement therapy: safe and efficacy of transdermal estriol and estradiol nanoparticles after 5 years follow-up study. Lat Am J Pharm. 2012;31(3):442-50.

12. Moghimi SM, Hunter AC, Murray JC. Nanomedicine: current status and future prospects. FASEB J. 2005; 19(3): 311-330, doi: 10.1096/fj.04-2747rev, indexed in Pubmed: 15746175.

13. Lehner R, Wang X, Marsch S, et al. Intelligent nanomaterials for medicine: carrier platforms and targeting strategies in the context of clinical application. Nanomedicine. 2013; 9(6): 742-757, doi: 10.1016/j. nano.2013.01.012, indexed in Pubmed: 23434677.

14. Boisseau P, Loubaton B. Nanomedicine, nanotechnology in medicine. Comptes Rendus Physique. 2011; 12(7): 620-636, doi: 10.1016/j. crhy.2011.06.001.

15. Esfandiari N. Production of Herceptin-Nanoparticles by chemical conjugation of Herceptin to Potato virus X. Iranian Journal of Breast Disease. 2013;6(3):17-27.

16. Bathe RS, Kapoor R. Transdermal Drug Delivery System: formulation, development and evaluation-An overview. International Journal of Biomedical and Advance Research. 2015;6(1):1-10.

17. Desai P, Patlolla RR, Singh M. Interaction of nanoparticles and cell-penetrating peptides with skin for transdermal drug delivery. Molecular membrane biology. 2010.

18. Alexander A, Dwivedi S, Giri TK, et al. Approaches for breaking the barriers of drug permeation through transdermal drug delivery. J Control Release. 2012; 164(1):26-40, doi: 10.1016/j.jconrel.2012.09.017, indexed in Pubmed: 23064010.

19. Rees M, Moghimi SM. Nanotechnology: from fundamental concepts to clinical applications for healthy aging. Nanomedicine: nanotechnology, biology, and medicine. 2012;8 Suppl 1:S1-4.

20. Gabellieri C, Frima H. Nanomedicine in the European Commission policy for nanotechnology. Nanomedicine. 2011; 7(5):519-520, doi: 10.1016/j. nano.2011.07.003, indexed in Pubmed: 21802394.

21. Botelho MA, Queiroz DB, Barros G, et al. Nanostructured transdermal hormone replacement therapy for relieving menopausal symptoms: a confocal Raman spectroscopy study. Clinics (Sao Paulo). 2014; 69(2): 75-82, doi: 10.6061/clinics/2014(02)01, indexed in Pubmed: 24519196.

22. Simon JA. ESTRASORB Study Group. Estradiol in micellar nanoparticles: the efficacy and safety of a novel transdermal drug-delivery technology in the management of moderate to severe vasomotor symptoms. Menopause. 2006; 13(2): 222-231, doi: 10.1097/01.gme.0000174096.56652.4f, indexed in Pubmed: 16645536.

23. Boxenbaum H, Muenz L. Pharmacokinetics of Estrasorb ${ }^{\circledR}$, a topical lotion for treatment of postmenopausal vasomotor symptoms. J Soc Gynecol Invest. 2002; 9: 238A.

24. Simon JA. Estradiol topical emulsion for the treatment of moderate-to-severe vasomotor symptoms associated with menopause. 2007.

25. Taylor MB, Gutierrez MJ. Absorption, bioavailability, and partner transfer of estradiol from a topical emulsion. Pharmacotherapy. 2008; 28(6): 712-718, doi: 10.1592/phco.28.6.712, indexed in Pubmed: 18503399.

26. Botelho M, Queiroz D, Carvalho C, et al. Effects of a transdermal testosterone metered-dose nanoemulsion in peri- and postmenopausal women: a novel protocol for treating low libido. Medical Express. 2015; 2(5), doi: 10.5935/medicalexpress.2015.05.03.

27. Escobar-Chávez JJ. Current Technologies to Increase the Transdermal Delivery of Drugs: Bentham Science Publishers; 2010.

28. Rees M, Moghimi SM, Rees M, et al. Nanotechnology: from fundamental concepts to clinical applications for healthy aging. Maturitas. 2012; 73(1): 1-4, doi: 10.1016/j.maturitas.2012.05.010, indexed in Pubmed: 22721807.

29. de Vargas BA, Bidone J, Oliveira LK, et al. Development of topical hydrogels containing genistein-loaded nanoemulsions. J Biomed Nanotechnol. 2012; 8(2): 330-336, indexed in Pubmed: 22515085.

30. Valenzuela P, Simon JA, Valenzuela $P$, et al. Nanoparticle delivery for transdermal HRT. Maturitas. 2012; 73(1): 74-80, doi: 10.1016/j.maturitas.2011.12.019, indexed in Pubmed: 22325243.

31. Chien T-Y. Transdermal hormone delivery system: compositions and methods. Google Patents; 2012.

32. Kheradmandnia S, Vasheghani-Farahani E, Nosrati M, et al. Preparation and characterization of ketoprofen-loaded solid lipid nanoparticles made from beeswax and carnauba wax. Nanomedicine. 2010;6(6): $753-$ 759, doi: 10.1016/j.nano.2010.06.003, indexed in Pubmed: 20599527.

33. Canonico M, Fournier A, Carcaillon L, et al. Postmenopausal hormone therapy and risk of idiopathic venous thromboembolism: results from the E3N cohort study. Arterioscler Thromb Vasc Biol. 2010; 30(2): 340345, doi: 10.1161/ATVBAHA.109.196022, indexed in Pubmed: 19834106.

34. OliéV Plu-Bureau G, Conard J, [et al]. Canonico M Scarabin P-Y Hormone therapy and recurrence of venous thromboembolism among postmenopausal women. Menopause. 2011;18(5):488-93.

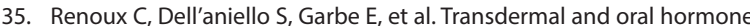
replacement therapy and the risk of stroke: a nested case-control study. BMJ. 2010; 340: c2519, indexed in Pubmed: 20525678. 